\title{
Targeting Macrophages as a Potential Therapeutic Intervention: Impact on Inflammatory Diseases and Cancer
}

\author{
Mirco Ponzoni *, Fabio Pastorino ${ }^{(\mathbb{D}}$, Daniela Di Paolo ${ }^{(\mathbb{D}}$, Patrizia Perri ${ }^{(\mathbb{D})}$ and Chiara Brignole * \\ Laboratory of Experimental Therapy in Oncology, Istituto Giannina Gaslini, Via G. Gaslini 5, 16147 Genoa, Italy; \\ fabiopastorino@gaslini.org (F.P.); danieladipaolo@gaslini.org (D.D.P.); patriziaperri@gaslini.org (P.P.) \\ * Correspondence: mircoponzoni@gaslini.org (M.P.); chiarabrignole@gaslini.org (C.B.); \\ Tel.: +39-10-56363539 (M.P.); +39-10-56363533 (C.B.); Fax: +39-10-3779820 (M.P. \& C.B.)
}

Received: 12 June 2018; Accepted: 30 June 2018; Published: 4 July 2018

\begin{abstract}
Macrophages, cells belonging to the innate immune system, present a high plasticity grade, being able to change their phenotype in response to environmental stimuli. They play central roles during development, homeostatic tissue processes, tissue repair, and immunity. Furthermore, it is recognized that macrophages are involved in chronic inflammation and that they play central roles in inflammatory diseases and cancer. Due to their large involvement in the pathogenesis of several types of human diseases, macrophages are considered to be relevant therapeutic targets. Nanotechnology-based systems have attracted a lot of attention in this field, gaining a pivotal role as useful moieties to target macrophages in diseased tissues. Among the different approaches that can target macrophages, the most radical is represented by their depletion, commonly obtained by means of clodronate-containing liposomal formulations and/or depleting antibodies. These strategies have produced encouraging results in experimental mouse models. In this review, we focus on macrophage targeting, based on the results so far obtained in preclinical models of inflammatory diseases and cancer. Pros and cons of these therapeutic interventions will be highlighted.
\end{abstract}

Keywords: macrophage targeting; macrophage depletion; nanomedicine; preclinical models; inflammatory diseases; cancer

\section{Introduction}

Macrophages, an essential component of the innate immune system, present heterogeneous functional phenotypes correlated to a high plasticity grade [1]. They play central roles in both physiological and pathological conditions, being involved in developmental and homeostatic tissue processes and in a plethora of human diseases. As a consequence, they have been deeply studied, and the idea to exploit them as therapeutic targets has focused the interest of experts of different research areas from inflammation to cancer.

At present, it is widely accepted that a variety of diseases (i.e., diabetes, atherosclerosis, rheumatoid arthritis, obesity, and cancer) are associated with chronic inflammation [2]. Furthermore, it is recognized that macrophages are the major players of chronic inflammation in most human diseases [1,3]. The knowledge about their biology, mechanisms of action, and activation phenotypes has been largely increased in the last few years. Macrophages have an innate and elevated propensity to adapt to the neighboring microenvironment and to rapidly change in response to environmental stimuli. Thus, it appears difficult to find out and design a unique therapeutic strategy based on macrophage modulation that is easily applicable to different kinds of human pathologies.

In the last decade, many studies have been addressed to understanding the mechanisms involved in macrophage activation and to relate them to macrophage function. The well-known 
bipolar model [4,5] distinguishes macrophages into two main different subsets: pro-inflammatory (M1, classically activated via interferon- $\gamma$ ) and anti-inflammatory (M2, alternatively activated via interleukin 4 and 13). However, a vast literature suggests that this is only a simplification, with M1 and M2 macrophages representing only the two extremes of a huge spectrum of activation states $[6,7]$. Indeed, this classification takes into consideration neither the fact that M1 and M2 stimuli do not exist as single entities in tissues, nor the source and the context of environmental stimuli. Moreover, the dichotomy of M1 and M2 macrophages derives from the pre-genomic era, when few markers were considered to establish differences and similarities in macrophage responses to stimuli [6]. Finally, it is important to underline that macrophages can also develop mixed M1/M2 phenotypes in different pathological conditions, where it is possible to find macrophages with intermediate activation status $[8,9]$.

Due to their large involvement in several high-impact diseases, macrophages have acquired a lot of interest as potential therapeutic targets. With this focus, several approaches have been developed, ranging from depletion to re-programming/re-polarization [10]. In this field, nanotechnology-based systems (i.e., liposomes, dendrimers, gold nanoparticles, and polymeric nanoparticles) have attracted attention [11,12], also due to their potential to be modified according to the disease site to be targeted. Furthermore, they have been demonstrated to be more effective than conventional delivery systems and with limited side effects [13]. In line with this, the understanding of the biology and the activation states of macrophages in different disease conditions has been, and will be in the near future, very helpful to design therapeutic protocols of personalized medicine.

Here, we reexamine the data obtained in preclinical mouse models of inflammatory diseases and cancer. In particular, the targeting of macrophages led to encouraging results, highlighting the possibility of translating these therapeutic interventions to the clinical practice.

\section{Macrophages in Health and Disease}

Macrophages are innate immune cells characterized by evolutionarily conserved functions, such as host defense against infection and tissue homeostasis. They were first identified by Metchnikoff in the late 19th century as tissue-residing immune cells belonging to the reticulum endothelial system and endowed with the ability to detect and phagocytose dying cells, harmful molecules, and pathogens [14,15]. A new classification was made in the 1970s, when van Furth and colleagues proposed macrophages as being part of the mononuclear phagocytic system (MPS) [16].

Based on their differential localization within the body, macrophages were also classified in discrete subsets as tissue-resident macrophages (TRM) [17]. They present different transcriptional profiles, associated to heterogeneous phenotypes, as a consequence of the tissue-specific function [7]. Primarily described as immune sentinels able to protect the tissue in which they are located, TRM are characterized by several steady-state functions. Indeed, in healthy tissues, they are responsible for homeostasis maintenance through the clearance of senescent cells and regulation of tissue metabolism. Based on their host tissue, they were defined as Langerhans cells in the skin, Kupffer cells in the liver, microglia within the brain, alveolar macrophages in the lung, peritoneal macrophages in the peritoneum, and osteoclasts in the bone. Initially, it was supposed that TRM were derived from circulating blood monocytes. At present, a new concept suggests that they can derive either from embryonic progenitors, seeding the tissues during development and being able to maintain their population independently from blood-borne precursors in adulthood, or from hematopoietic stem cell-derived circulating monocytes [18].

For many years, it has been accepted as a paradigm model that macrophages can adopt opposite activation states in response to environmental stimuli sensed primarily by Toll-like receptors. Based on this assumption, they have been distinguished as classically (M1) and alternatively (M2) activated macrophages. M1 and M2 macrophages are pro-inflammatory and anti-inflammatory, respectively. The main activities associated to M1/M2 phenotypes can be summarized as "Fight" for M1 macrophages and "Fix" for M2 macrophages. These two diverse programs take place as a 
response to environmental stimuli through enzymatic pathways responsible for arginine catabolism [5]. Macrophages that follow the "Fight" program, thanks to inducible nitric oxide synthase (iNOS), convert arginine to citrulline and nitric oxide (NO), inhibiting cell proliferation and inducing cancer cell death. On the other hand, macrophages activating the "Fix" program are able to promote cell proliferation and repair, via the metabolism of arginine through arginase I (ArgI), that produces ornithine and urea.

Notably, it is clear that, at present, the extraordinary plasticity of macrophages is not limited to these two opposed phenotypes, representing only the extremes of a wide and continuous array of activation states $[19,20]$.

The concept that macrophages take part as major players in a series of human diseases associated with chronic inflammation has been a matter of debate for a long time. At present, much evidence supports this theory and a vast literature is dedicated to this field. Furthermore, many efforts have been made to understand the role of macrophages in inflammation and cancer and to reveal the different phenotypes they can acquire in inflammation-driven pathological conditions. Although the dichotomy of M1 versus M2 does not entirely satisfy the reality, it is acknowledged that under pathological conditions, macrophages can be found in both the activation states.

In the last decade, researchers have tried to decipher which polarization/phenotype is associated to a specific inflammation-related disease. The findings obtained led to the understanding that, in most of the pathological conditions analyzed, macrophages can temporally acquire different phenotypes, due to the evolution of the disease.

\subsection{Inflammatory Diseases}

Several studies evidenced the importance of macrophages in diseases such as asthma, atherosclerosis, rheumatoid arthritis, osteoarthritis, endometriosis, diabetes type 1 and 2, and obesity.

In asthma, Zaslona and colleagues demonstrated the role of alveolar macrophages, concluding that resident alveolar macrophages play a protective role during the early phase of allergic lung inflammation. On the other hand, they stated that the recruited monocytes, putative precursors of alveolar macrophages, are involved in asthma pathogenesis by promoting lung inflammation [21]. Moreover, Jiang and colleagues recently updated the role of macrophages in asthma, concluding that both M1 and M2 subsets participate in asthma pathogenesis, being alternately predominant in the different phases of the disease [22]. The aforementioned situation, with M1 and M2 macrophages that alternate their predominance under pathological conditions, is found in several other human pathologies.

In atherosclerosis, a chronic inflammatory disease characterized by the narrowing and thickening of the arteries caused by buildup of plaque around the artery wall, macrophages participate in all the stages of the disease, being involved in pathogenesis and progression [23]. Summarily, pro-inflammatory macrophages are implicated in plaque initiation and progression, while the anti-inflammatory ones are involved in plaque stabilization. Furthermore, it has been reported that both macrophage subtypes (M1/M2) can be found in atherosclerotic plaques, where they are differently distributed [24].

In rheumatoid arthritis, a common autoimmune disorder characterized by chronic arthritis that leads to joint destruction, macrophages have a leading role in pathogenesis and disease progression. It has been reported that an increased number of sublining macrophages in the synovium is an early hallmark of active rheumatic disease. Furthermore, the degree of synovial macrophage infiltration is strictly related to joint erosion [25]. In the context of rheumatoid arthritis, the phenotype of the macrophages is heterogeneous and still needs to be completely elucidated. Of note, in synovial tissues and fluids, macrophages can present both pro-inflammatory and anti-inflammatory phenotypes [26].

In osteoarthritis, not commonly recognized as an inflammatory disease, macrophages directly participate in synovial inflammation through the production of TNF- $\alpha$ and IL- $1 \beta$ and, indirectly, through the activation of synovial fibroblasts [27]. 
Recently, the contribution of macrophages in metabolic diseases such as diabetes [28] and in obesity-related adipose inflammation, frequently associated with the development of insulin resistance and type 2 diabetes, has been also reported [29].

\subsection{Cancer}

Inflammatory cells have been recognized as a key component of the tumor microenvironment (TME), which can be represented as an ecological niche playing a critical role in cancer development, progression, and control. Within this niche, a complex interplay between different cell types (proliferating cancer cells, stromal cells, and infiltrating immune cells) leads to the establishment of a microenvironment, whose components influence each other to promote tumor progression. Macrophages are the dominant portion of infiltrating leukocytes in all tumors, where they are defined as tumor-associated macrophages (TAMs) and are mostly characterized by an M2-like phenotype [30]. They mainly derive from circulating monocytes, recruited at the tumor site by chemotactic factors.

Macrophages participate in both tumor initiation and development/progression. It is now accepted that non-malignant TME cells, being macrophages the most prominent ones, play a tumor-initiating role, generating a persistent inflammatory response against environmental stimuli [31,32]. Indeed, it has been reported that different inflammatory conditions (i.e., inflammatory bowel disease, Crohn's disease, asbestosis, etc.) are highly correlated with the increased risk of cancer development [33]. Noteworthy, macrophages involved in the phase of tumor initiation are characterized by a pro-inflammatory phenotype. Once the tumor is established, macrophages switch to an anti-inflammatory phenotype. It is customary to say that macrophages are educated by neoplastic cells to acquire a protumor phenotype [32,34,35].

TAMs support tumor progression through different mechanisms, promoting angiogenesis and tumor spreading at distant sites and creating an immunosuppressive environment [36]. Furthermore, it seems that different subsets of TAMs can be found at the tumor site, where they can be either temporally distinguished, depending on disease evolution, or geographically determined on the basis of their location. In this regard, macrophages found in hypoxic areas of the tumor are prevalently involved in tumor angiogenesis, while those residing at the tumor-stroma interface take part in invasion and metastasis [30,37].

TAMs are abundant in established tumors and their presence is often associated with increased tumor progression and invasion [32]. Indeed, preclinical and clinical evidence shows that a prevalence of TAMs within tumors is associated with a worse overall prognosis in a high proportion of solid tumors (i.e., breast cancer, ovarian cancer, melanoma, etc.; Table 1) [38-44]. Until now, to our knowledge, only in a few cases (i.e., colorectal cancer and non-small cell lung cancer) it has been reported that a high density of macrophages is associated with improved overall survival [45-47]. Doubtful is the role of TAMs in gastric cancer; a study by Ohno and colleagues proves, indeed, their positive correlation with improved survival [48], while more recent papers demonstrate that an high infiltration of TAMs is a predictor of poor prognosis for gastric cancer patients $[49,50]$. 
Table 1. Prognostic significance of macrophages in tumors. TAMs: tumor-associated macrophages, M1:pro-inflammatory, M2: anti-inflammatory.

\begin{tabular}{clll}
\hline Cancer Type & \multicolumn{1}{c}{ Prognosis Association } & References \\
\hline Melanoma & $\begin{array}{l}\text { M2 TAMs accumulation in malignant melanoma was confirmed as } \\
\text { biomarker of poor prognosis. }\end{array}$ & [43] Falleni, M. et al. \\
\hline Breast & $\begin{array}{l}\text { High density of TAMs was associated with malignant phenotype and poor } \\
\text { survival in breast cancer patients, emerging as a novel prognostic factor. }\end{array}$ & [40] Zhao, X. et al. \\
\hline Ovarian Cancer & $\begin{array}{l}\text { High CD163 }{ }^{+} \text {TAMs infiltration was associated with poor prognosis, while } \\
\text { a high M1/M2 ratio predicted better prognosis. }\end{array}$ & [41] Yuan, X. et al. \\
\hline Bladder Cancer & $\begin{array}{l}\text { A high TAMs count was associated with a lower 5-year survival rate with } \\
\text { respect to low TAMs count, and it was proposed as a predictor of } \\
\text { clinical outcome. }\end{array}$ & [44] Hanada, T. et al. \\
\hline Colorectal Cancer & $\begin{array}{l}\text { Macrophage infiltration was associated with improved patient survival. } \\
\text { No difference in prognosis was found in patients with different ratios of } \\
\text { M1/M2 infiltration. }\end{array}$ & [45] Edin, S. et al. \\
\hline Non-small cell lung cancer & $\begin{array}{l}\text { Independently of the density of CD68 }{ }^{+} \text {TAMs, the localization and M1/M2 } \\
\text { polarization were suggested as potential prognostic markers. }\end{array}$ & [42] Mei, J. et al. \\
\hline
\end{tabular}

\section{Macrophage Targeting}

Despite macrophages being characterized by an elevated grade of plasticity, they have been the interest of researchers as potential therapeutic targets. They can acquire different phenotypes, frequently overlapping each others, in response to the continuous environmental stimuli they are subjected to. For these reasons, the design of therapeutic interventions has been very challenging, due most of all to the lack of unambiguous markers that can identify and distinguish pathological macrophages from their safe and useful counterparts. Several strategies have been pursued and adopted with the aim of manipulating macrophages, and their re-education and depletion can be considered the most important methods. In this scenario, nanotechnology-based systems have been greatly implicated and have led to important results in preclinical models [51-53].

\subsection{Macrophage Re-Education}

Macrophage re-education is one of the most promising strategies realized in the field of anticancer therapy, aimed at re-programming M2-like, protumor TAMs to M1-like macrophages endowed with antitumor functions $[36,54]$. In this field, nanotechnology-based systems have been explored, resulting as being applicable for successful preclinical achievements [12]. Recently, Song and colleagues [55] used bioconjugated manganese dioxide nanoparticles to efficiently prime TAMs to an antitumor M1-like phenotype, also resulting in higher sensitivity and response to chemotherapy, via the reduction of tumor hypoxia, in a murine breast cancer model.

Furthermore, Zanganeh and colleagues demonstrated that ferumoxytal nanoparticles significantly inhibited tumor growth in a breast cancer model, with an increased number of M1 macrophages at the tumor site [56]. In the same work, ferumoxital nanoparticles were able to inhibit liver and lung metastases in a mouse model of small cell lung cancer. Also in this case, metastases reduction was paralleled by the reversal of TAMs to the tumoricidal M1 phenotype.

An interesting study performed by Ortega and colleagues [57] demonstrated that mannosylated nanoparticles (Mn-NPs), encapsulating small interfering RNAs (siRNAs) against $\mathrm{I} \kappa \mathrm{B} \alpha$, were able to selectively target TAMs via the mannose receptor (CD206) and to restore the NF- $\mathrm{kB}$ signaling pathways, finally resulting in the induction of cytotoxic and immunostimulatory functions of TAMs in vitro. In a previous work, the same authors demonstrated that Mn-NPs are biocompatible and able to enhance the uptake of TAMs in vivo [58]. This last finding enables one to envisage that the proposed Mn-NPs could be translated to the in vivo setting.

Huang and colleagues developed a nucleic acid-encapsulating carrier endowed with two important features: (1) selectivity for TAMs (targeted to the macrophage galactose-type lectin I) and (2) microenvironment-responsiveness ( $\mathrm{pH}$-sensitive). These nanocarriers, encapsulating anti-IL-10 
and anti-IL-10R oligonucleotides, were tested in a preclinical mouse model of liver cancer, and were demonstrated to be effective in suppressing the protumor functions of TAMs, stimulating their antitumor activities [59].

\subsection{Macrophage Depletion}

In pathological conditions, the more radical approach used to block macrophages is represented by their direct killing, named "macrophage depletion". This strategy is based on the use of either depleting antibodies, such as anti-colony-stimulating factor 1 receptor (anti-CSF1R), or molecules exerting a specific toxicity against macrophages, such as bisphosphonates (i.e., clodronate and zoledronic acid) and trabectedin.

\subsubsection{Monoclonal Antibodies to the Colony-Stimulating Factor 1 Receptor}

In a recent study performed in colorectal adenocarcinoma and fibrosarcoma mouse models, the depletion of TAMs was obtained by the use of a high-affinity humanized anti-colony-stimulating factor 1 receptor (CSF1R) monoclonal antibody (RG7155) [60]. The treatment with RG7155 induced a selective apoptosis of $\mathrm{CSF}_{1} \mathrm{R}^{+} \mathrm{CD} 163^{+}$M2-like macrophages, but not of $\mathrm{CD} 80^{+}$M1-like macrophages, in vitro, and depleted TAMs in tumor-bearing mice. This was also paralleled by an increase of cytotoxic effector $\mathrm{CD} 8^{+} \mathrm{T}$ cells, followed by delayed tumor growth and metastases formation.

In cervical and mammary carcinoma mouse models, the depletion of TAMs, obtained by means of a highly selective CSF1R inhibitor, resulted in the arrest and delay of tumor growth, respectively. Moreover, the depletion of macrophages was paralleled by the increase of $\mathrm{CD}^{+} \mathrm{T}$ cells infiltrating cervical and breast carcinomas [61].

More recently, the evaluation of the safety, pharmacokinetics, pharmacodynamics, and antitumor activity of a fully human antibody against CSF1R (AMG 820) in a first-in-humans phase-I study for advanced solid tumors was published [62]. This study demonstrated that the anti-CSF1R antibody AMG 820 was tolerated with manageable toxicity up to $20 \mathrm{mg} / \mathrm{kg}$ every two weeks. Nevertheless, the treatment with AMG 820 as the single agent resulted in limited antitumor activity.

\subsubsection{Liposomal Bisphosphonates}

Liposomes, self-closed structures characterized by one or more phospholipid bilayers delimiting an inner aqueous space, were developed many years ago, and soon after demonstrated their great potential as vehicles for drug delivery [63-65]. Since their discovery more than 50 years ago, they have been a matter of extensive investigation, finding applicability in different medical areas. At present, due to both biological and technological features, they are considered to be the most successful drug delivery systems developed to date [66]. Several liposomal formulations are in clinical trials and some of them have been already released on the market for the cure of different kind of diseases $[65,67]$.

The use of liposomes for drug delivery and their consequent therapeutic efficacy strictly depend on their physicochemical properties, with size and membrane charge being the most important ones [65]. Indeed, the fate of administered liposomes is closely associated to their physical features. For these reasons, researchers have been focusing their attention on the optimization of methods to synthesize liposomes suitable for in vivo use. Indeed, the inherent liposome composition renders them as extremely versatile and safe tools for medical purposes, due to their high biocompatibility and biodegradability, low immunogenicity, and drug protection.

Depending on the nature of the diseased tissues to be targeted, it is important to take into account the overall dimension of the liposome-based cargos [68,69]. Indeed, inflammatory or solid tumor tissues are characterized by enhanced vascular permeability. This feature can be exploited by nanocarriers of appropriate size (namely 50-100 nm), which can passively enter the leaky vessels of pathological tissues, accumulating at the target site. This phenomenon is known as the enhanced permeability and retention effect (EPR) and it is of particular interest for drug-loaded liposomes used for cancer treatment $[70,71]$. On the other hand, larger liposomes easily interact with plasma proteins 
undergoing opsonisation, a prerequisite for their recognition and capture by cells of the reticulum endothelial system (RES). The uptake of liposomes by phagocytes of the RES can be prevented by the surface modification of the liposomes themselves. Regarding this matter, the most used method is represented by the insertion of polyethylene glycol (PEG) chains at the liposome surface with the aid of cross-linker lipids [72-74]. Outer membrane modification with PEG (a method defined as "PEGylation") confers to liposomes stealth features, leading to increased blood circulation time, a great characteristic for drug-delivery systems suitable for application in cancer therapy [75].

As underlined before, liposomes present the inherent property to target mononuclear phagocytic cells. This feature can be exploited in the case of a macrophage-targeted therapy. In this regard, large multilamellar clodronate-contained liposomes were developed by van Rooijen and colleagues in the 1990s as specific tools for the transient depletion of macrophages [76]. Clodronate belongs to the drug family of bisphosphonates and is used for the treatment of osteolytic bone disease and post menopausal osteoporosis because of its ability to inhibit osteoclast function [77].

Large clodronate liposomes, due to their big size, are rapidly recognized and taken up by macrophages. Once captured and ingested by them, clodronate liposomes are exposed to lysosomal phospholipases that, after degradation of the phospholipid bilayer, lead to the release of the entrapped drug within the cytoplasmic compartment of the cells. This, in turn, causes apoptotic cell death via an ATP-dependent mechanism [76]. This technique is called "liposome-mediated macrophage suicide".

Clodronate liposomes can efficiently deplete tissue-resident macrophages of different body districts, preferentially depending on the route of administration [78]. Indeed, Kupffer cells, spleen macrophages, and bone marrow macrophages can be depleted by intravenous injection (i.v.) of clodronate liposomes, while intraperitoneal injection (i.p.) is needed for peritoneal macrophages. Moreover, the subcutaneous (s.c.) administration is able to deplete macrophages of the draining lymph nodes.

\subsection{Nanomedicine and Macrophage Functionality: Disease Models}

This section focuses on the application of macrophage depletion in a series of mouse disease models.

\subsubsection{Inflammatory Diseases}

Rheumatoid arthritis is one of the first inflammatory diseases in which liposomal clodronate was applied $[79,80]$. In experimental mouse models of arthritis, a single intraarticular injection of clodronate liposomes determined the reversible depletion of synovial phagocytic cells, accompanied by the reduction of cartilage destruction $[79,80]$. In an open study conducted on rheumatoid arthritis-affected patients scheduled for knee joint replacement, a single intraarticular injection of clodronate liposomes led to effective macrophage depletion in the synovial lining [81]. Moreover, the depletion of macrophages in the lining was also paralleled by a significant reduction of the expression of adhesion molecules, such as ICAM-1 and VCAM-1. These molecules are widely expressed in the synovium of rheumatoid arthritis patients. Of note, the procedure was well tolerated and resulted as being nontoxic. This last study represents, to our knowledge, the only example of macrophage depletion performed in humans. The results obtained are very important and encouraging for further investigation in this field and for designing protocols to be applied in the treatment of rheumatoid arthritis.

In a study conducted by $\mathrm{Bu}$ and colleagues, it was concluded that visceral adipose tissue macrophages (VATMs) can be regarded as a potential target for the development of drugs to be used for both the prevention and therapy of obesity and obesity-related complications [82]. Indeed, in a high-fat-diet animal model, the depletion of VATMs obtained by intraperitoneal injection of clodronate liposomes blocked the high-fat-induced weight gain and the development of insulin resistance. Gene expression analysis demonstrated that VATMs depletion was associated to the downregulation of genes involved in lipogenesis and gluconeogenesis. 
Similar results were also obtained by Feng and colleagues, which demonstrated that the intraperitoneal injection of clodronate liposomes in diet-induced obese (DIO) mice reduced VATMs and improved systemic glucose homeostasis and insulin sensitivity. This was also paralleled by increased blood levels of the insulin-sensitizing hormone adiponectin [83].

Endometriosis, although its pathogenesis is still matter of debate, can be considered to be a chronic inflammatory disease that affects a large fraction of menstruating women. It is characterized by the growth of vascularized endometrial tissue in aberrant locations outside of the uterus, principally the pelvis, and it is associated with symptoms such as chronic pelvic pain, dysmenorrhea, and reduced fertility $[84,85]$. The endometriosis process is also accompanied by altered immune surveillance in the local peritoneal microenvironment. It has been reported that infiltrating macrophages are abundant in endometriotic lesions, where they contribute to the production of elevated amounts of pro-inflammatory and chemotactic cytokines.

In this context, the depletion of macrophages by the use of clodronate liposomes was very useful to understand their role in the establishment and development of the disease. In an experimental mouse model of endometriosis [86], clodronate liposomes were i.p. injected at different time points, with respect to the implantation of the endometrium. Two different treatment protocols were performed. In the first one, macrophages were depleted at early times; specifically, clodronate liposomes were injected at days 0,4 , and 8 from the implantation of the endometrial tissue in recipient mice. Clodronate liposomes significantly reduced the percentage of F4/80- and CD11b-positive cells in the peritoneum of sacrificed animals, with respect to mice treated with PBS-containing liposomes. This was also accompanied by a significant reduction in the weight of endometriotic lesions. These data indicate that, in the absence of macrophages, the syngeneic endometrium retains the ability to adhere to the peritoneal layer; nevertheless, the lesions fail to grow. In the second set of experiments, macrophages were depleted at later times ( 4 and 8 days after lesion engraftment), when endometriotic lesions had already been established and organized. In this case, macrophages depletion did not affect the number of endometriotic lesions, which was similar in treated and untreated animals. However, the total weight of lesions was significantly lower in mice subjected to ablative treatment. The results obtained indicated that the recruitment of the macrophages into the lesions is not only an early event sufficient for the initial development of the lesions, but it is also a necessary step for their subsequent successful establishment. These findings are straightforward because they suggest that it could be possible to treat human endometriosis by depleting local macrophages. Furthermore, it has been established that macrophages in the peritoneal fluid and/or those infiltrating the endometriotic lesions of patients express markers of alternative activation, such as CD163 (hemoglobin scavenger receptor) and CD206. In the forthcoming future, it can be envisaged to develop new formulations of clodronate liposomes directly targeted to these antigens. Due to the fact that macrophages have also a protective function and are involved in homeostatic tissue processes, the possibility of selectively targeting a specific subset of them is of particular interest for the development of patient-tailored treatment protocols.

Several studies have been also conducted on inflammatory diseases of the lung, such as granulomatous inflammation in response to Mycobacterium tuberculosis and chronic obstructive pulmonary disease (COPD). COPD is a life-threatening inflammatory disease of the lung characterized by chronic airway inflammation, mucus hypersecretion, and airway remodeling. In a cigarette smoke-induced COPD mouse model, Beckett and colleagues provided evidence for the pivotal role of macrophages in the pathogenesis of the disease [87]. Indeed, macrophage depletion in the lung, obtained by means of intranasal administration of clodronate liposomes given along an 8-week period of smoke exposure, resulted in a reduced smoke-induced epithelial thickening and emphysema development. Furthermore, macrophage depletion also determined protection against alteration of the lung function.

In a mouse model of pulmonary tuberculosis, it was demonstrated that the depletion of alveolar macrophages (AM), achieved by intranasal delivery of clodronate liposomes, was able to protect mice from lethality. AM depletion was associated with reduced outgrowth of mycobacteria in lungs and 
liver and to a polarized production of type-I cytokines in the lung tissue; moreover, AM-depleted mice displayed deficient granuloma formation. These results provide new insights for the design of novel therapeutic strategies against intracellular bacterial diseases [88].

\subsubsection{Cancer}

The direct killing of TAMs is a strategy aimed at eradicating macrophages at tumor sites, with the intention to abolish and/or interrupt the network of signals that favors tumor growth and progression.

Zhan and colleagues used a glucomannan polysaccharide with high affinity for the mannose receptor to specifically deliver alendronate (ALN) to TAMs. In both in vitro and in vivo experiments, this ALN-glucomannan bioconjugated formulation preferentially accumulated into macrophages, leading them to undergo apoptosis. Furthermore, in a subcutaneous sarcoma mouse model, the intratumor injection of ALN-glucomannan bioconjugated formulation determined the effective depletion of TAMs at the tumor site, reduced angiogenesis, led to the recovery of local immune surveillance, and significantly reduced tumor progression [89].

Hattori and colleagues tested the effectiveness of folate (FL)-decorated zoledronic acid (ZOL)-encapsulating liposomes in inhibiting tumor angiogenesis and tumor growth in a murine colon adenocarcinoma model. Here, although the FL-ZOL liposomes were able to induce selective cytotoxicity in vitro via the folate receptor, a severe toxicity limited their use in vivo [90].

Clodronate liposomes have been successfully applied in various mouse models of cancer with the aim of depleting macrophages at the tumor site. Banciu and colleagues demonstrated that the depletion of TAMs in a murine melanoma model was associated with a reduction of tumor volume [91]. Moreover, in a teratocarcinoma model, the depletion of TAMs resulted in the inhibition of tumor angiogenesis and in the inhibition of tumor growth [92]. In a chemically induced mouse lung adenocarcinoma model, the effective depletion of TAMs by means of clodronate liposomes was paralleled by a $50 \%$ reduction of tumor burden and tumor cell proliferation, as detected by the Ki67 marker, with respect to control animals treated with a vehicle only [93]. In this model, the treatment was more effective in slowing the growth of larger tumors, while the overall number of lung tumor nodules was not affected, being similar in treated and control mice.

Nevertheless, one of the major concerns of the use of clodronate liposomes to deplete TAMs relies on the fact that ablating strategies may also compromise the protective functions of macrophages themselves. Indeed, therapeutic approaches based on macrophage depletion have been associated with an increased risk of infection [94]. For this reason, our laboratory recently developed a new clodronate-containing liposomal formulation able to reach the tumor site without being massively detected and taken up by the cells of the MPS. The development of liposomes of appropriate physicochemical properties (i.e., size, Z-potential, and membrane modification) leads to the depletion of macrophages at different sites. Indeed, as already described before, large-sized liposomes are rapidly taken up by phagocytic cells [65], representing an excellent tool to preferentially target tissue macrophages rather than TAMs. Thus, to safely reach the tumor site, avoiding early recognition by the MPS, liposomes are subjected to PEGylation [74,95].

In a recent study, Piaggio and colleagues developed a new liposomal formulation of clodronate (Clo-Lipo-DOTAP) characterized by stealth features and small size, necessary to gain long circulating time and EPR-mediated tumor targeting properties, respectively. Moreover, the new formulation was not toxic (blood levels of kidney and liver markers were not altered), was cell-specific (immune cells other than macrophages were not affected), and resulted effective at clodronate dosage from 5 to 10 times lower than that used in previous studies [53].

Clo-Lipo-DOTAP were used in two xenograft mouse models of melanoma, the first one resembling the hallmarks of early stage primary tumor, and the second representing the lung metastatic behavior of advanced melanoma [53]. In both cases, the treatment with Clo-Lipo-DOTAP showed inhibition of tumor growth. In the primary tumor model, the depletion of TAMs determined a reduction of the volume of the subcutaneous tumors; this was further accompanied by a reduced tumor vascularization. 
In the metastatic melanoma model, the antitumor effect driven by TAMs depletion was evident in the significant decrease of pulmonary tumor nodules, also paralleled by a reduction of tumor microvessel density.

Plasma levels of a number of cytokines, chemokines, and growth factors involved in and/or related to TAMs polarization, chemoattraction, and functions (IL-10, Mo KC, TNF- $\alpha$, VEGF, and PDGF-bb) were statistically decreased in Clo-Lipo-DOTAP-treated mice with respect to controls. This result further highlights the antitumor efficacy of this new formulation.

Interestingly, tumor masses of treated animals, although significantly smaller with respect to controls, present a proliferating index comparable to that derived from tumors of untreated mice [53], as underlined by a similar percentage of Ki67-positive nuclei. These findings clearly indicate that the antitumor effectiveness, obtained after the depletion of TAMs, was derived from the inhibition of tumor angiogenesis and from the reduction of inflammatory-related signals, while it was not the result of direct tumor cell killing. All together, these data are encouraging and suggest that this approach could be used, in combination with first-line therapy, for the treatment of advanced-stage melanoma. Indeed, despite the recent application of promising protocols based on immunotherapy and targeted therapy [96], melanoma continues to be a very challenging tumor (Table 2).

Table 2. Nanomedicine and macrophage functionality: macrophage depletion in disease models. i.t.: intratracheal; i.v.: intravenous; s.c.: subcutaneous; i.p.: intraperitoneum; i.a.: intraarticular.

\begin{tabular}{|c|c|c|c|}
\hline Disease Model & $\begin{array}{c}\text { Clodronate Liposomal } \\
\text { (Administration Schedule) }\end{array}$ & Achievements & References \\
\hline Rheumatoid arthritis & $\begin{array}{l}\text { Single i.a. injection of clodronate } \\
\text { liposomes in a mouse model } \\
\text { of arthritis. } \\
\text { Single i.a. injection of clodronate } \\
\text { liposomes in rheumatoid } \\
\text { arthritis-affected patients }\end{array}$ & $\begin{array}{l}\text { (1) The reversible depletion of synovial } \\
\text { macrophages was accompanied by the } \\
\text { reduction of cartilage destruction. } \\
\text { (2) The effective depletion of macrophages in } \\
\text { the synovial lining was paralleled by the } \\
\text { reduction of adhesion molecules (ICAM-1 } \\
\text { and VCAM-1 in the lining). }\end{array}$ & $\begin{array}{l}\text { [79] van Lent P.L. et al. } \\
\text { [80] van Lent P.L. et al. } \\
\text { [81] Barrera P. et al. }\end{array}$ \\
\hline Endometriosis & $\begin{array}{l}\text { I treatment schedule: } \\
\text { clodronate liposomes were i.p. injected } \\
\text { at days } 0,4 \text {, and } 8 \text { with respect to the } \\
\text { injection of endometrial tissues in } \\
\text { recipient mice. } \\
\text { II treatment schedule: } \\
\text { clodronate liposomes were i.p. injected } \\
\text { at days } 4 \text { and } 8 \text { with respect to } \\
\text { endometriotic lesions implantation. }\end{array}$ & $\begin{array}{l}\text { I schedule: significant reduction of } \mathrm{F} 4 / 80^{+} \text {and } \\
\mathrm{CD} 11 \mathrm{~b}^{+} \text {cells in the peritoneum of sacrificed mice } \\
\text { was observed with respect to those treated with } \\
\text { PBS-containing liposomes. Reduction in the } \\
\text { weight of endometriotic lesions. } \\
\text { II schedule: the delayed treatment did not affect } \\
\text { the number of endometriotic lesions, while their } \\
\text { total weight was statistically reduced. }\end{array}$ & [86] Bacci M. et al. \\
\hline $\begin{array}{c}\text { Melanoma (B16/F10 } \\
\text { mouse melanoma } \\
\text { model) }\end{array}$ & $\begin{array}{l}\text { Clo-Lipo-DOTAP formulation was } \\
\text { administered i.v., starting } 7 \text { days after } \\
\text { B16/F10 cells inoculum, and was } \\
\text { repeated } 3 \text { times with 3-day interval } \\
\text { between injections. The same schedule } \\
\text { was used for both s.c. and metastatic } \\
\text { model. }\end{array}$ & $\begin{array}{l}\text { s.c. model: depletion of TAMs was associated } \\
\text { with a reduction of tumor volumes and reduced } \\
\text { tumor vascularization. } \\
\text { Metastatic model: reduction of pulmonary tumor } \\
\text { nodules and decreased tumor microvessel } \\
\text { density was observed. }\end{array}$ & [53] Piaggio F. et al. \\
\hline
\end{tabular}

\section{Conclusions and Future Perspectives}

The nanotechnology-based systems described in this review and intended to manipulate macrophages in both inflammatory diseases and cancer have been demonstrated to be beneficial in improving the outcome in preclinical mouse models, holding promise for the future design of therapeutic interventions (Table 3). However, it appears evident that macrophage-targeted therapies are intrinsically characterized by limitations. Indeed, their effectiveness is closely related to an in-progress therapeutic window. In fact, the phenotypic re-reversal and re-population of macrophages in the case of re-education and depletion strategies, respectively, can occur after the discontinuance of the treatment. 
Table 3. Nanotechnology-based systems and macrophage manipulation in preclinical models. ODNs: oligonucleotides.

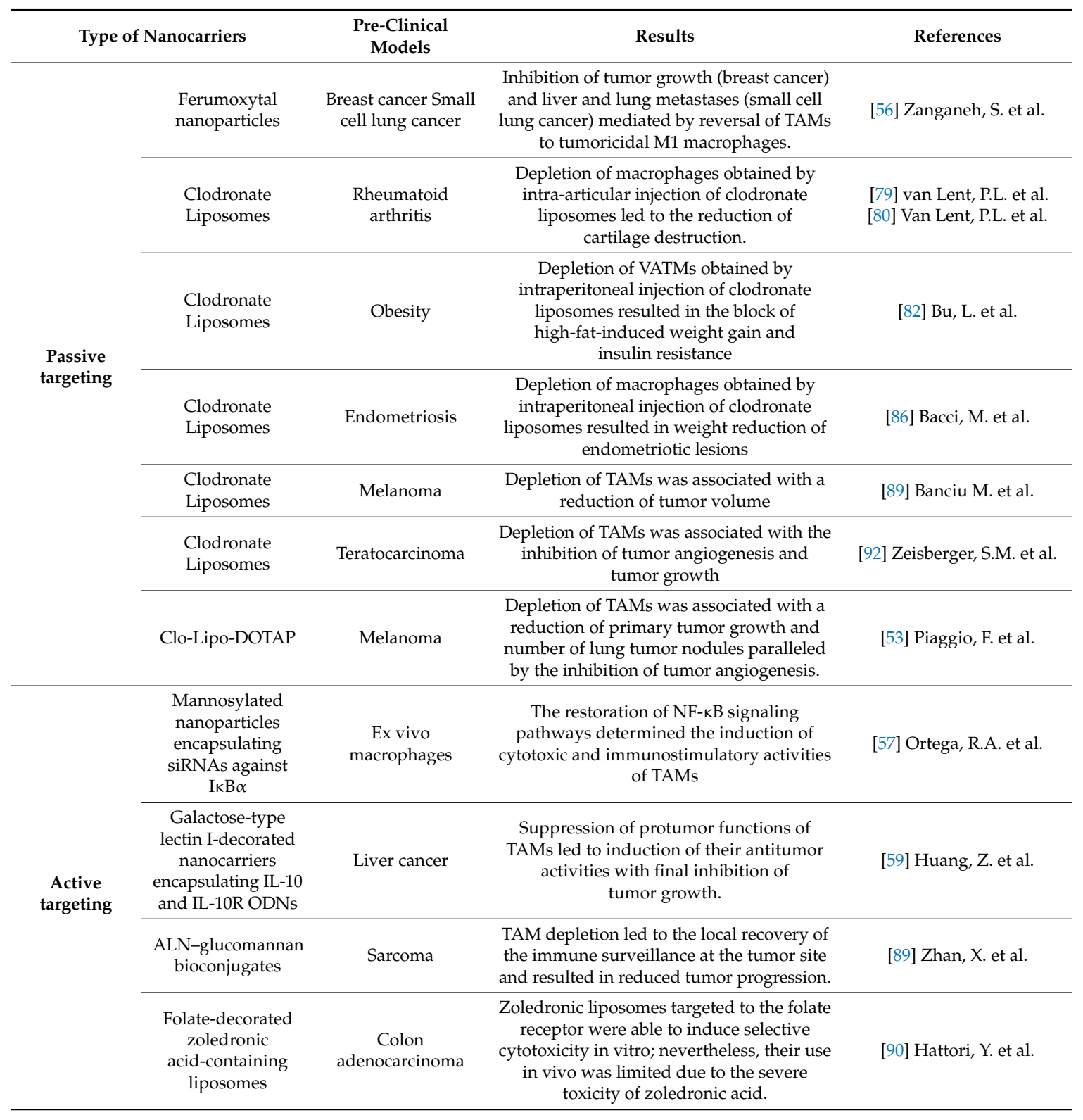

Moreover, the overall challenge that nanotechnology-based systems have to face is represented by their poor selectivity. The continuous changes in phenotype/activation state that macrophages adopt in response to the constant environmental stimuli result in the unspecific targeting of tissue-resident macrophages, which play a pivotal role in tissue homeostasis and body defense. Indeed, the depletion of macrophages is frequently associated to increased risk of infection [97].

The aforementioned limitations determine the need to find novel treatments able to balance the cost-benefit ratio of this approach. More durable and specifically targeted interventions might be necessary to obtain long-lasting results, while sparing resident macrophages. In light of new insights on the activation states and related markers of macrophages in several human diseases, it is reasonable to hypothesize that it will be feasible to develop, in the near future, new nanocarriers targeted to specific subsets of macrophages involved in the pathogenesis and/or progression of a given pathology.

As a note of caution, we think that further investigations are needed to attempt translating the results so far obtained to the clinic. Indeed, despite the positive results obtained in preclinical 
studies and the proof-of-concept clinical study performed on rheumatoid arthritis [81], to our knowledge, no approved clinical trials are currently running and/or recruiting patients. The lack of translation to the clinical practice could be due to the intrinsic limitation related to the method of macrophage depletion and to the main obstacles usually faced by nanodelivery systems (i.e., pharmaceutical manufacturing, government regulations, intellectual properties), issues already reviewed elsewhere [75]. Moreover, the phase-I study performed with the use of the anti-CSF1R antibody also revealed its limits, supporting the hypothesis that this therapeutic approach might be applied only in a combination therapy [62]. In our opinion, a treatment strategy based on the combination of macrophage re-programming and macrophage depletion, which could result in a more deep and long-lasting microenvironment priming, should lead to improved therapeutic results in both inflammatory diseases and cancer. In this regard, a nanotechnology-based system could be an exceptionally suitable moiety. The development of nanocarriers decorated with macrophage-specific ligands and loaded with a combination of molecules for both macrophage killing and re-programming would, indeed, represents a true step ahead to design innovative protocols for macrophage-driven pathologies. This would pave the way for future patient-tailored therapies.

Author Contributions: C.B. participated to the conception and design of the study, collection of the data, and drafting of the manuscript. M.P., F.P., D.D.P., and P.P. participated in revising and discussing the accuracy and the intellectual content of the manuscript and to approving its final version.

Funding: This work was partially funded by a grant from the Associazione Italiana Ricerca Cancro (AIRC IG 18474 to M.P.).

Conflicts of Interest: The authors declare no conflict of interest.

\section{References}

1. Wynn, T.A.; Chawla, A.; Pollard, J.W. Macrophage biology in development, homeostasis and disease. Nature 2013, 496, 445-455. [CrossRef] [PubMed]

2. Schultze, J.L.; Schmieder, A.; Goerdt, S. Macrophage activation in human diseases. Semin. Immunol. 2015, 27, 249-256. [CrossRef] [PubMed]

3. Mantovani, A.; Biswas, S.K.; Galdiero, M.R.; Sica, A.; Locati, M. Macrophage plasticity and polarization in tissue repair and remodelling. J. Pathol. 2013, 229, 176-185. [CrossRef] [PubMed]

4. Sica, A.; Mantovani, A. Macrophage plasticity and polarization: In vivo veritas. J. Clin. Investig. 2012, 122, 787-795. [CrossRef] [PubMed]

5. Mills, C.D. M1 and M2 Macrophages: Oracles of Health and Disease. Crit. Rev. Immunol. 2012, 32, 463-488. [CrossRef] [PubMed]

6. Martinez, F.O.; Gordon, S. The M1 and M2 paradigm of macrophage activation: Time for reassessment. F1000Prime Rep. 2014, 6, 13. [CrossRef] [PubMed]

7. Gautier, E.L.; Shay, T.; Miller, J.; Greter, M.; Jakubzick, C.; Ivanov, S.; Helft, J.; Chow, A.; Elpek, K.G.; Gordonov, S.; et al. Gene-expression profiles and transcriptional regulatory pathways that underlie the identity and diversity of mouse tissue macrophages. Nat. Immunol. 2012, 13, 1118-1128. [CrossRef] [PubMed]

8. Vogel, D.Y.; Vereyken, E.J.; Glim, J.E.; Heijnen, P.D.; Moeton, M.; van der Valk, P.; Amor, S.; Teunissen, C.E.; van Horssen, J.; Dijkstra, C.D. Macrophages in inflammatory multiple sclerosis lesions have an intermediate activation status. J. Neuroinflamm. 2013, 10, 809. [CrossRef] [PubMed]

9. Pettersen, J.S.; Fuentes-Duculan, J.; Suarez-Farinas, M.; Pierson, K.C.; Pitts-Kiefer, A.; Fan, L.; Belkin, D.A.; Wang, C.Q.; Bhuvanendran, S.; Johnson-Huang, L.M.; et al. Tumor-associated macrophages in the cutaneous SCC microenvironment are heterogeneously activated. J. Investig. Dermatol. 2011, 131, 1322-1330. [CrossRef] [PubMed]

10. Schultze, J.L. Reprogramming of macrophages-New opportunities for therapeutic targeting. Curr. Opin. Pharmacol. 2016, 26, 10-15. [CrossRef] [PubMed]

11. Singh, Y.; Pawar, V.K.; Meher, J.G.; Raval, K.; Kumar, A.; Shrivastava, R.; Bhadauria, S.; Chourasia, M.K. Targeting tumor associated macrophages (TAMs) via nanocarriers. J. Control. Release 2017, 254, 92-106. [CrossRef] [PubMed] 
12. Andon, F.T.; Digifico, E.; Maeda, A.; Erreni, M.; Mantovani, A.; Alonso, M.J.; Allavena, P. Targeting tumor associated macrophages: The new challenge for nanomedicine. Semin. Immunol. 2017, 34, 103-113. [CrossRef] [PubMed]

13. Shi, J.; Votruba, A.R.; Farokhzad, O.C.; Langer, R. Nanotechnology in drug delivery and tissue engineering: From discovery to applications. Nano Lett. 2010, 10, 3223-3230. [CrossRef] [PubMed]

14. Davies, L.C.; Jenkins, S.J.; Allen, J.E.; Taylor, P.R. Tissue-resident macrophages. Nat. Immunol. 2013, 14, 986-995. [CrossRef] [PubMed]

15. Tauber, A.I. Metchnikoff and the phagocytosis theory. Nat. Rev. Mol. Cell Biol. 2003, 4, 897-901. [CrossRef] [PubMed]

16. Van Furth, R.; Cohn, Z.A.; Hirsch, J.G.; Humphrey, J.H.; Spector, W.G.; Langevoort, H.L. Mononuclear phagocytic system: New classification of macrophages, monocytes and of their cell line. Bull. World Health Organ. 1972, 47, 651-658. [PubMed]

17. Epelman, S.; Lavine, K.J.; Randolph, G.J. Origin and functions of tissue macrophages. Immunity 2014, 41, 21-35. [CrossRef] [PubMed]

18. Dey, A.; Allen, J.; Hankey-Giblin, P.A. Ontogeny and polarization of macrophages in inflammation: Blood monocytes versus tissue macrophages. Front. Immunol. 2014, 5, 683. [CrossRef] [PubMed]

19. Murray, P.J.; Allen, J.E.; Biswas, S.K.; Fisher, E.A.; Gilroy, D.W.; Goerdt, S.; Gordon, S.; Hamilton, J.A.; Ivashkiv, L.B.; Lawrence, T.; et al. Macrophage activation and polarization: Nomenclature and experimental guidelines. Immunity 2014, 41, 14-20. [CrossRef] [PubMed]

20. Guilliams, M.; Ginhoux, F.; Jakubzick, C.; Naik, S.H.; Onai, N.; Schraml, B.U.; Segura, E.; Tussiwand, R.; Yona, S. Dendritic cells, monocytes and macrophages: A unified nomenclature based on ontogeny. Nat. Rev. Immunol. 2014, 14, 571-578. [CrossRef] [PubMed]

21. Zaslona, Z.; Przybranowski, S.; Wilke, C.; van Rooijen, N.; Teitz-Tennenbaum, S.; Osterholzer, J.J.; Wilkinson, J.E.; Moore, B.B.; Peters-Golden, M. Resident alveolar macrophages suppress, whereas recruited monocytes promote, allergic lung inflammation in murine models of asthma. J. Immunol. 2014, 193, 4245-4253. [CrossRef] [PubMed]

22. Jiang, Z.; Zhu, L. Update on the role of alternatively activated macrophages in asthma. J. Asthma Allergy 2016, 101-107. [CrossRef] [PubMed]

23. Moore, K.J.; Sheedy, F.J.; Fisher, E.A. Macrophages in atherosclerosis: A dynamic balance. Nat. Rev. Immunol. 2013, 13, 709-721. [CrossRef] [PubMed]

24. Bobryshev, Y.V.; Ivanova, E.A.; Chistiakov, D.A.; Nikiforov, N.G.; Orekhov, A.N. Macrophages and Their Role in Atherosclerosis: Pathophysiology and Transcriptome Analysis. Biomed. Res. Int. 2016, 9582430. [CrossRef] [PubMed]

25. Udalova, I.A.; Mantovani, A.; Feldmann, M. Macrophage heterogeneity in the context of rheumatoid arthritis. Nat. Rev. Rheumatol. 2016, 12, 472-485. [CrossRef] [PubMed]

26. Li, J.; Hsu, H.C.; Mountz, J.D. Managing macrophages in rheumatoid arthritis by reform or removal. Curr. Rheumatol. Rep. 2012, 14, 445-454. [CrossRef] [PubMed]

27. Bondeson, J.; Wainwright, S.D.; Lauder, S.; Amos, N.; Hughes, C.E. The role of synovial macrophages and macrophage-produced cytokines in driving aggrecanases, matrix metalloproteinases, and other destructive and inflammatory responses in osteoarthritis. Arthritis Res. Ther. 2006, 8, R187. [CrossRef] [PubMed]

28. Hill, A.A.; Reid Bolus, W.; Hasty, A.H. A decade of progress in adipose tissue macrophage biology. Immunol. Rev. 2014, 262, 134-152. [CrossRef] [PubMed]

29. Weisberg, S.P.; McCann, D.; Desai, M.; Rosenbaum, M.; Leibel, R.L.; Ferrante, A.W., Jr. Obesity is associated with macrophage accumulation in adipose tissue. J. Clin. Investig. 2003, 112, 1796-1808. [CrossRef] [PubMed]

30. Lewis, C.E.; Pollard, J.W. Distinct role of macrophages in different tumor microenvironments. Cancer Res. 2006, 66, 605-612. [CrossRef] [PubMed]

31. Balkwill, F.R.; Mantovani, A. Cancer-related inflammation: Common themes and therapeutic opportunities. Semin. Cancer Biol. 2012, 22, 33-40. [CrossRef] [PubMed]

32. Noy, R.; Pollard, J.W. Tumor-associated macrophages: From mechanisms to therapy. Immunity 2014, 41, 49-61. [CrossRef] [PubMed]

33. Coussens, L.M.; Werb, Z. Inflammation and cancer. Nature 2002, 6917, 860-867. [CrossRef] [PubMed]

34. Pollard, J.W. Tumour-educated macrophages promote tumour progression and metastasis. Nat. Rev. Cancer 2004, 1, 71-78. [CrossRef] [PubMed] 
35. Stout, R.D.; Watkins, S.K.; Suttles, J. Functional plasticity of macrophages: In situ reprogramming of tumor-associated macrophages. J. Leukoc. Biol. 2009, 86, 1105-1109. [CrossRef] [PubMed]

36. Mantovani, A.; Marchesi, F.; Malesci, A.; Laghi, L.; Allavena, P. Tumour-associated macrophages as treatment targets in oncology. Nat. Rev. Clin. Oncol. 2017, 14, 399-416. [CrossRef] [PubMed]

37. Pollard, J.W. Macrophages define the invasive microenvironment in breast cancer. J. Leukoc. Biol. 2008, 84, 623-630. [CrossRef] [PubMed]

38. Zhang, Q.W.; Liu, L.; Gong, C.Y.; Shi, H.S.; Zeng, Y.H.; Wang, X.Z.; Zhao, Y.W.; Wei, Y.Q. Prognostic significance of tumor-associated macrophages in solid tumor: A meta-analysis of the literature. PLOS ONE 2012, 7, e50946. [CrossRef] [PubMed]

39. Bingle, L.; Brown, N.J.; Lewis, C.E. The role of tumour-associated macrophages in tumour progression: Implications for new anticancer therapies. J. Pathol. 2002, 196, 254-265. [CrossRef] [PubMed]

40. Zhao, X.; Qu, J.; Sun, Y.; Wang, J.; Liu, X.; Wang, F.; Zhang, H.; Wang, W.; Ma, X.; Gao, X.; et al. Prognostic significance of tumor-associated macrophages in breast cancer: A meta-analysis of the literature. Oncotarget 2017, 8, 30576-30586. [CrossRef] [PubMed]

41. Yuan, X.; Zhang, J.; Li, D.; Mao, Y.; Mo, F.; Du, W.; Ma, X. Prognostic significance of tumor-associated macrophages in ovarian cancer: A meta-analysis. Gynecol. Oncol. 2017, 147, 181-187. [CrossRef] [PubMed]

42. Mei, J.; Xiao, Z.; Guo, C.; Pu, Q.; Ma, L.; Liu, C.; Lin, F.; Liao, H.; You, Z.; Liu, L. Prognostic impact of tumor-associated macrophage infiltration in non-small cell lung cancer: A systemic review and meta-analysis. Oncotarget 2016, 7, 34217-34228. [CrossRef] [PubMed]

43. Falleni, M.; Savi, F.; Tosi, D.; Agape, E.; Cerri, A.; Moneghini, L.; Bulfamante, G.P. M1 and M2 macrophages' clinicopathological significance in cutaneous melanoma. Melanoma Res. 2017, 27, 200-210. [CrossRef] [PubMed]

44. Hanada, T.; Nakagawa, M.; Emoto, A.; Nomura, T.; Nasu, N.; Nomura, Y. Prognostic value of tumor-associated macrophage count in human bladder cancer. Int. J. Urol. 2000, 7, 263-269. [CrossRef] [PubMed]

45. Edin, S.; Wikberg, M.L.; Oldenborg, P.A.; Palmqvist, R. Macrophages: Good guys in colorectal cancer. Oncoimmunology 2013, 2, e23038. [CrossRef] [PubMed]

46. Forssell, J.; Oberg, A.; Henriksson, M.L.; Stenling, R.; Jung, A.; Palmqvist, R. High macrophage infiltration along the tumor front correlates with improved survival in colon cancer. Clin. Cancer Res. 2007, 13, 1472-1479. [CrossRef] [PubMed]

47. Welsh, T.J.; Green, R.H.; Richardson, D.; Waller, D.A.; O’Byrne, K.J.; Bradding, P. Macrophage and mast-cell invasion of tumor cell islets confers a marked survival advantage in non-small-cell lung cancer. J. Clin. Oncol. 2005, 23, 8959-8967. [CrossRef] [PubMed]

48. Ohno, S.; Inagawa, H.; Dhar, D.K.; Fujii, T.; Ueda, S.; Tachibana, M.; Suzuki, N.; Inoue, M.; Soma, G.; Nagasue, N. The degree of macrophage infiltration into the cancer cell nest is a significant predictor of survival in gastric cancer patients. Anticancer Res. 2003, 23, 5015-5022. [PubMed]

49. Zhang, J.; Yan, Y.; Yang, Y.; Wang, L.; Li, M.; Wang, J.; Liu, X.; Duan, X.; Wang, J. High Infiltration of Tumor-Associated Macrophages Influences Poor Prognosis in Human Gastric Cancer Patients, Associates with the Phenomenon of EMT. Medicine 2016, 95, e2636. [CrossRef] [PubMed]

50. Wang, X.L.; Jiang, J.T.; Wu, C.P. Prognostic significance of tumor-associated macrophage infiltration in gastric cancer: A meta-analysis. Genet. Mol. Res. 2016, 15. [CrossRef] [PubMed]

51. Ahsan, F.; Rivas, I.P.; Khan, M.A.; Torres Suarez, A.I. Targeting to macrophages: Role of physicochemical properties of particulate carriers-Liposomes and microspheres-On the phagocytosis by macrophages. J. Control. Release 2002, 79, 29-40. [CrossRef]

52. Lee, W.H.; Loo, C.Y.; Traini, D.; Young, P.M. Nano- and micro-based inhaled drug delivery systems for targeting alveolar macrophages. Expert Opin. Drug Deliv. 2015, 12, 1009-1026. [CrossRef] [PubMed]

53. Piaggio, F.; Kondylis, V.; Pastorino, F.; Di Paolo, D.; Perri, P.; Cossu, I.; Schorn, F.; Marinaccio, C.; Murgia, D.; Daga, A.; et al. A novel liposomal Clodronate depletes tumor-associated macrophages in primary and metastatic melanoma: Anti-angiogenic and anti-tumor effects. J. Control. Release 2016, 165-177. [CrossRef] [PubMed]

54. Aras, S.; Zaidi, M.R. TAMeless traitors: Macrophages in cancer progression and metastasis. Br. J. Cancer 2017, 117, 1583-1591. [CrossRef] [PubMed] 
55. Song, M.; Liu, T.; Shi, C.; Zhang, X.; Chen, X. Bioconjugated Manganese Dioxide Nanoparticles Enhance Chemotherapy Response by Priming Tumor-Associated Macrophages toward M1-like Phenotype and Attenuating Tumor Hypoxia. ACS Nano 2016, 10, 633-647. [CrossRef] [PubMed]

56. Zanganeh, S.; Hutter, G.; Spitler, R.; Lenkov, O.; Mahmoudi, M.; Shaw, A.; Pajarinen, J.S.; Nejadnik, H.; Goodman, S.; Moseley, M.; et al. Iron oxide nanoparticles inhibit tumour growth by inducing pro-inflammatory macrophage polarization in tumour tissues. Nat. Nanotechnol. 2016, 11,986-994. [CrossRef] [PubMed]

57. Ortega, R.A.; Barham, W.; Sharman, K.; Tikhomirov, O.; Giorgio, T.D.; Yull, F.E. Manipulating the NF-kappaB pathway in macrophages using mannosylated, siRNA-delivering nanoparticles can induce immunostimulatory and tumor cytotoxic functions. Int. J. Nanomed. 2016, 2163-2177. [CrossRef] [PubMed]

58. Ortega, R.A.; Barham, W.J.; Kumar, B.; Tikhomirov, O.; McFadden, I.D.; Yull, F.E.; Giorgio, T.D. Biocompatible mannosylated endosomal-escape nanoparticles enhance selective delivery of short nucleotide sequences to tumor associated macrophages. Nanoscale 2015, 7, 500-510. [CrossRef] [PubMed]

59. Huang, Z.; Zhang, Z.; Jiang, Y.; Zhang, D.; Chen, J.; Dong, L.; Zhang, J. Targeted delivery of oligonucleotides into tumor-associated macrophages for cancer immunotherapy. J. Control. Release 2012, 158, $286-292$. [CrossRef] [PubMed]

60. Ries, C.H.; Cannarile, M.A.; Hoves, S.; Benz, J.; Wartha, K.; Runza, V.; Rey-Giraud, F.; Pradel, L.P.; Feuerhake, F.; Klaman, I.; et al. Targeting tumor-associated macrophages with anti-CSF-1R antibody reveals a strategy for cancer therapy. Cancer Cell 2014, 25, 846-859. [CrossRef] [PubMed]

61. Strachan, D.C.; Ruffell, B.; Oei, Y.; Bissell, M.J.; Coussens, L.M.; Pryer, N.; Daniel, D. CSF1R inhibition delays cervical and mammary tumor growth in murine models by attenuating the turnover of tumor-associated macrophages and enhancing infiltration by $\mathrm{CD}^{+} \mathrm{T}$ cells. Oncoimmunology 2013, 2, e26968. [CrossRef] [PubMed]

62. Papadopoulos, K.P.; Gluck, L.; Martin, L.P.; Olszanski, A.J.; Tolcher, A.W.; Ngarmchamnanrith, G.; Rasmussen, E.; Amore, B.M.; Nagorsen, D.; Hill, J.S.; et al. First-in-Human Study of AMG 820, a Monoclonal Anti-Colony-Stimulating Factor 1 Receptor Antibody, in Patients with Advanced Solid Tumors. Clin. Cancer Res. 2017, 23, 5703-5710. [CrossRef] [PubMed]

63. Gregoriadis, G. Drug entrapment in liposomes. FEBS Lett. 1973, 36, 292-296. [CrossRef]

64. Gregoriadis, G.; Ryman, B.E. Liposomes as carriers of enzymes or drugs: A new approach to the treatment of storage diseases. Biochem. J. 1971, 124, 58P. [CrossRef] [PubMed]

65. Allen, T.M.; Cullis, P.R. Liposomal drug delivery systems: From concept to clinical applications. Adv. Drug Deliv. Rev. 2013, 65, 36-48. [CrossRef] [PubMed]

66. Felice, B.; Prabhakaran, M.P.; Rodriguetablez, A.P.; Ramakrishna, S. Drug delivery vehicles on a nano-engineering perspective. Mater. Sci. Eng. C Mater. Biol. Appl. 2014, 178-195. [CrossRef] [PubMed]

67. Bozzuto, G.; Molinari, A. Liposomes as nanomedical devices. Int. J. Nanomed. 2015, 975-999. [CrossRef] [PubMed]

68. Euliss, L.E.; DuPont, J.A.; Gratton, S.; DeSimone, J. Imparting size, shape, and composition control of materials for nanomedicine. Chem. Soc. Rev. 2006, 35, 1095-1104. [CrossRef] [PubMed]

69. Debbage, P. Targeted drugs and nanomedicine: Present and future. Curr. Pharm. Des. 2009, 15, $153-172$. [CrossRef] [PubMed]

70. Gabizon, A.A. Selective tumor localization and improved therapeutic index of anthracyclines encapsulated in long-circulating liposomes. Cancer Res. 1992, 52, 891-896. [PubMed]

71. Peer, D.; Karp, J.M.; Hong, S.; Farokhzad, O.C.; Margalit, R.; Langer, R. Nanocarriers as an emerging platform for cancer therapy. Nat. Nanotechnol. 2007, 2, 751-760. [CrossRef] [PubMed]

72. Immordino, M.L.; Dosio, F.; Cattel, L. Stealth liposomes: Review of the basic science, rationale, and clinical applications, existing and potential. Int. J. Nanomed. 2006, 1, 297-315.

73. Ishida, T.; Harashima, H.; Kiwada, H. Interactions of liposomes with cells in vitro and in vivo: Opsonins and receptors. Curr. Drug Metab. 2001, 2, 397-409. [CrossRef] [PubMed]

74. Gabizon, A.A. Stealth liposomes and tumor targeting: One step further in the quest for the magic bullet. Clin. Cancer Res. 2001, 7, 223-225. [PubMed]

75. Sercombe, L.; Veerati, T.; Moheimani, F.; Wu, S.Y.; Sood, A.K.; Hua, S. Advances and Challenges of Liposome Assisted Drug Delivery. Front.Pharmacol. 2015, 6, 286. [CrossRef] [PubMed] 
76. Van Rooijen, N.; Sanders, A. Liposome mediated depletion of macrophages: Mechanism of action, preparation of liposomes and applications. J. Immunol Methods 1994, 174, 83-93. [CrossRef]

77. Ghinoi, V.; Brandi, M.L. Clodronate: Mechanisms of action on bone remodelling and clinical use in osteometabolic disorders. Expert Opin. Pharmacother. 2002, 3, 1643-1656. [CrossRef] [PubMed]

78. van Rooijen, N.; van Kesteren-Hendrikx, E. Clodronate liposomes: Perspectives in research and therapeutics. J. Liposome Res. 2002, 12, 81-94. [CrossRef] [PubMed]

79. Van Lent, P.L.; van den Bersselaar, L.; van den Hoek, A.E.; van de Ende, M.; Dijkstra, C.D.; van Rooijen, N.; van de Putte, L.B.; van den Berg, W.B. Reversible depletion of synovial lining cells after intra-articular treatment with liposome-encapsulated dichloromethylene diphosphonate. Rheumatol. Int. 1993, 13, 21-30. [CrossRef] [PubMed]

80. Van Lent, P.L.; Holthuysen, A.E.; Van Rooijen, N.; Van De Putte, L.B.; Van Den Berg, W.B. Local removal of phagocytic synovial lining cells by clodronate-liposomes decreases cartilage destruction during collagen type II arthritis. Ann. Rheum. Dis. 1998, 57, 408-413. [CrossRef] [PubMed]

81. Barrera, P.; Blom, A.; van Lent, P.L.; van Bloois, L.; Beijnen, J.H.; van Rooijen, N.; de Waal Malefijt, M.C.; van de Putte, L.B.; Storm, G.; van den Berg, W.B. Synovial macrophage depletion with clodronate-containing liposomes in rheumatoid arthritis. Arthritis Rheum. 2000, 43, 1951-1959. [CrossRef]

82. Bu, L.; Gao, M.; Qu, S.; Liu, D. Intraperitoneal injection of clodronate liposomes eliminates visceral adipose macrophages and blocks high-fat diet-induced weight gain and development of insulin resistance. AAPS J. 2013, 15, 1001-1011. [CrossRef] [PubMed]

83. Feng, B.; Jiao, P.; Nie, Y.; Kim, T.; Jun, D.; van Rooijen, N.; Yang, Z.; Xu, H. Clodronate liposomes improve metabolic profile and reduce visceral adipose macrophage content in diet-induced obese mice. PLoS ONE 2011, 6, e24358. [CrossRef] [PubMed]

84. Capobianco, A.; Rovere-Querini, P. Endometriosis, a disease of the macrophage. Front. Immunol. $2013,4,9$. [CrossRef] [PubMed]

85. Ahn, S.H.; Monsanto, S.P.; Miller, C.; Singh, S.S.; Thomas, R.; Tayade, C. Pathophysiology and Immune Dysfunction in Endometriosis. Biomed. Res. Int. 2015, 795976. [CrossRef] [PubMed]

86. Bacci, M.; Capobianco, A.; Monno, A.; Cottone, L.; Di Puppo, F.; Camisa, B.; Mariani, M.; Brignole, C.; Ponzoni, M.; Ferrari, S.; et al. Macrophages are alternatively activated in patients with endometriosis and required for growth and vascularization of lesions in a mouse model of disease. Am. J. Pathol. 2009, 175, 547-556. [CrossRef] [PubMed]

87. Beckett, E.L.; Stevens, R.L.; Jarnicki, A.G.; Kim, R.Y.; Hanish, I.; Hansbro, N.G.; Deane, A.; Keely, S.; Horvat, J.C.; Yang, M.; et al. A new short-term mouse model of chronic obstructive pulmonary disease identifies a role for mast cell tryptase in pathogenesis. J. Allergy Clin. Immunol. 2013, 131, 752-762. [CrossRef] [PubMed]

88. Leemans, J.C.; Juffermans, N.P.; Florquin, S.; van Rooijen, N.; Vervoordeldonk, M.J.; Verbon, A.; van Deventer, S.J.; van der Poll, T. Depletion of alveolar macrophages exerts protective effects in pulmonary tuberculosis in mice. J. Immunol. 2001, 166, 4604-4611. [CrossRef] [PubMed]

89. Zhan, X.; Jia, L.; Niu, Y.; Qi, H.; Chen, X.; Zhang, Q.; Zhang, J.; Wang, Y.; Dong, L.; Wang, C. Targeted depletion of tumour-associated macrophages by an alendronate-glucomannan conjugate for cancer immunotherapy. Biomaterials 2014, 35, 10046-10057. [CrossRef] [PubMed]

90. Hattori, Y.; Yamashita, J.; Sakaida, C.; Kawano, K.; Yonemochi, E. Evaluation of antitumor effect of zoledronic acid entrapped in folate-linked liposome for targeting to tumor-associated macrophages. J. Liposome Res. 2015, 25, 131-140. [CrossRef] [PubMed]

91. Banciu, M.; Metselaar, J.M.; Schiffelers, R.M.; Storm, G. Antitumor activity of liposomal prednisolone phosphate depends on the presence of functional tumor-associated macrophages in tumor tissue. Neoplasia 2008, 10, 108-117. [CrossRef] [PubMed]

92. Zeisberger, S.M.; Odermatt, B.; Marty, C.; Zehnder-Fjallman, A.H.; Ballmer-Hofer, K.; Schwendener, R.A. Clodronate-liposome-mediated depletion of tumour-associated macrophages: A new and highly effective antiangiogenic therapy approach. Br. J. Cancer. 2006, 95, 272-281. [CrossRef] [PubMed]

93. Fritz, J.M.; Tennis, M.A.; Orlicky, D.J.; Lin, H.; Ju, C.; Redente, E.F.; Choo, K.S.; Staab, T.A.; Bouchard, R.J.; Merrick, D.T.; et al. Depletion of tumor-associated macrophages slows the growth of chemically induced mouse lung adenocarcinomas. Front Immunol. 2014, 5, 587. [CrossRef] [PubMed] 
94. Purnama, C.; Ng, S.L.; Tetlak, P.; Setiagani, Y.A.; Kandasamy, M.; Baalasubramanian, S.; Karjalainen, K.; Ruedl, C. Transient ablation of alveolar macrophages leads to massive pathology of influenza infection without affecting cellular adaptive immunity. Eur. J. Immunol. 2014, 44, 2003-2012. [CrossRef] [PubMed]

95. Li, S.D.; Huang, L. Stealth nanoparticles: High density but sheddable PEG is a key for tumor targeting. J. Control. Release 2010, 145, 178-181. [CrossRef] [PubMed]

96. Postow, M.A.; Callahan, M.K.; Wolchok, J.D. Immune Checkpoint Blockade in Cancer Therapy. J. Clin. Oncol. 2015, 33, 1974-1982. [CrossRef] [PubMed]

97. Schneider, C.; Nobs, S.P.; Heer, A.K.; Kurrer, M.; Klinke, G.; van Rooijen, N.; Vogel, J.; Kopf, M. Alveolar macrophages are essential for protection from respiratory failure and associated morbidity following influenza virus infection. PLoS Pathog. 2014, 10, e1004053. [CrossRef] [PubMed]

C 2018 by the authors. Licensee MDPI, Basel, Switzerland. This article is an open access article distributed under the terms and conditions of the Creative Commons Attribution (CC BY) license (http://creativecommons.org/licenses/by/4.0/). 